\title{
LAS ELECCIONES LEGISLATIVAS DEL 27 DE MAYO DE 1984 Y LA APERTURA DEMOCRATICA EGIPCIA
}

Gema Martín Muñoz

Desde que, en 1952, Egipto obtuvo la independencia efectiva por medio de la revolución de julio, su evolución política ha pasado por tres etapas que, por el fuerte carácter presidencialista del régimen, coinciden con los tres presidentes que hasta ahora han gobernado este país. Nasser, padre del socialismo árabe, que recuperó, desde una posición de no alineamiento, la soberanía nacional y sentó las bases de un régimen que sirvió de modelo para futuras revoluciones árabes, pero en el que la ausencia de la democracia estuvo siempre presente a través de la dictadura del partido único. Sadat, que se desvió hacia un pro occidentalismo que le obligó a una liberalización económica y política —en la que se enmarca el tratado de Camp David- que generó tensiones sociales, políticas y hasta religiosas, culminando con su asesinato, y cuyo aperturismo limitado, del que, además, dio marcha atrás, en la realidad siguió reduciendo el juego político a las mismas fuerzas dentro del régimen. Y la tercera etapa que vive ahora Egipto con la presidencia de Mubarak, que si bien se inició dentro del continuismo con lo que Sadat había significado, comenzó un proceso de cambio encaminado hacia un avance democrático y un aumento de las libertades.

Las bases fundamentales de ese cambio quedaron reflejadas en las elecciones legislativas de mayo de 1984 , primeras bajo este presidente y de cuyo análisis y estudio se pueden extraer los primeros balances - la proximidad 
cronológica de los hechos no permite hacer un balance definitivo de todo el proceso político, ya que no es una etapa aún concluida - de hasta qué punto estas elecciones han supuesto un paso definitivo hacia una transición democrática que cuenta con el apoyo de la población y de cuál es la nueva situación histórica y política del Egipto de hoy, país cuya importancia cualitativa dentro del marco árabe es muy destacable.

\section{LOS CAMBIOS DE LA REVOLUCION DE 1952}

Lo que en julio de 1952 parecía ser sólo un golpe de Estado tomó rápidamente la amplitud de una verdadera revolución que modificó la organización política del país y sus estructuras económicas y sociales.

El 18 de junio de 1953, la Monarquía es abolida y le sucede una República presidida, durante un corto tiempo, por el general Neguib y, después, por Nasser hasta su muerte. En este nuevo período de la historia egipcia, un nuevo grupo social va a controlar los mandos del poder: los oficiales del Ejército. Desde la caída del antiguo régimen, los militares ocuparán los puestos claves de la Administración y de la diplomacia.

En los primeros tiempos de la revolución, hasta la guerra de Suez, aunque se llevó a cabo la reforma agraria, las medidas económicas fueron moderadas y las inversiones privadas, locales y extranjeras, no disminuyeron e incluso se incrementaron (especialmente por la Ley núm. 156 de 1953 y la Ley núm. 430 de 1954, que concedían exenciones de impuestos y facilidades para transferir las ganancias fuera del país). Sin embargo, el Gobierno empezó a asumir un creciente papel en la vida económica, representado especialmente por el Consejo Nacional de Producción y el Consejo Nacional de Servicios, que incluía un proyecto con una inversión de 400 millones de $£ E$ en que la construcción de la gran presa de Assuan tenía máxima prioridad '.

Por otro lado, el régimen político instaurado por la revolución acabó con el multipartidismo y redujo el juego político al partido único, que en un primer momento se denominó Reagrupamiento de la Liberación.

En política exterior se inició, desde la asistencia de Nasser en 1955 a la cumbre de Bandung, lo que se convertiría en la postura del «no alineamiento positivo» que siempre defendería el carismático raís.

El 26 de junio de 1956 se ratificaron por doble referéndum una nueva Constitución, que concedía enormes poderes al presidente y dejaba en un papel de figuración a la Asamblea, y la designación de Nasser como presidente de la República. Dos meses después tenía lugar la crisis de Suez, a raíz de la cual se produjeron relevantes cambios: se inician medidas de «egipcianización» de compañías de seguros, agencias comerciales y bancos extranjeros,

1 Véase, sobre la política económica del régimen de Nasser, John WATERBURY, The Egypt of Nasser and Sadat. The Political Economy of Two Regimes, Londres, 1983. 
que en un plazo máximo de cinco años debían convertirse en sociedades anónimas pertenecientes a autóctonos y dirigidas por egipcios de nacimiento. Queda claro que las sociedades inglesas y francesas no gozaban de este plazo.

La guerra de Suez motivó la necesidad de asegurar la independencia real del país, estableciendo un mayor dirigismo efectivo sobre la economía. También produjo la desaparición del Reagrupamiento de la Liberación, pasando a crearse la Unión Nacional a partir de mayo de 1957, que en principio se proponía encuadrar las masas con el fin de movilizarlas en la obra de la reconstrucción nacional.

De esta manera, el 3 y 14 de julio de 1957 se convocaron elecciones generales cuyo carácter era claramente no competitivo: sólo existían candidatos del partido único, que eran previamente seleccionados por el Comité Ejecutivo de la Unión Nacional. De 2.508 candidatos iniciales, el Comité escogió 1.188 para las 284 circunscripciones.

En 1956 había sido promulgada una nueva ley electoral (Ley núm. 73 de 1956) que presentaba tres grandes novedades con respecto a la ley vigente en la época monárquica: aplicación del sufragio directo, reducción de la edad para votar de veinticinco a dieciocho años y concesión del derecho del voto a la mujer. Por lo demás, el sistema electoral se mantuvo igual al del período anterior: mayoría absoluta por el procedimiento de candidaturas individuales.

Los resultados demostraron, según apuntó Anouar Abdel Malek ${ }^{2}$, que quienes tuvieron acceso a los escaños de la Asamblea Nacional fueron en su mayoría todos los sectores de la burguesía egipcia, con la representación de sólo cuatro obreros.

La Asamblea de 1957 apenas tuvo una vigencia de medio año, pues la formación de la República Arabe Unida, con Siria, hizo necesaria una nueva Constitución y un nuevo planteamiento de la composición de la Cámara. Con esta unión se iniciaba la idea que siempre persiguió a Nasser de realizar la unidad árabe bajo la égida egipcia y que fue seguida de otras tentativas posteriores, aún menos fructuosas, con Irak, Yemen, Sudán, Libia...

La disolución de la RAU a los casi tres años de su formación, tras el golpe de Estado en Siria del 28 de septiembre de 1961, llevó al líder egipcio a otra orientación política ante la necesidad de encontrar nuevas bases de apoyo a su régimen. Este cambio quedó plasmado en su proyecto de Carta Nacional en 1962. En ella planteaba un nuevo orden social basado en principios socialistas, que se enmarcaban en un concepto de "democracia social», dando un enfoque populista a su política. En base a esto se estableció que la mitad de los miembros de cualquier organización representativa, incluyendo a la Asamblea Nacional, debían ser obreros y campesinos.

Es también en este contexto cuando se multiplican las nacionalizaciones, y el partido único, la Unión Nacional, pasa a denominarse Unión Socialista

2 A. Abdel Malek, Egipto Sociedad Militar (traducción de Roberto Mesa), Madrid, 1967, pp. 145-146. 
Arabe (USA). La diferencia entre ambas difiere poco en su estructura, aunque, según Nasser, ésta estribaba en la apertura de la primera a todos, mientras la segunda haría una severa criba y rechazaría de sus filas a los «oportunistas» y «explotadores». Como ha muy bien indicado Nada Tomiche, «las razones del fracaso de los anteriores partidos únicos no parece que se deban únicamente al maquiavelismo de los enemigos políticos, sino también a deficiencias humanas: los comités elegidos están democráticamente compuestos de campesinos, obreros... pero los miembros carecen de la formación y experiencia necesarias para la buena marcha de una célula política. Antes de formar los reagrupamientos o los partidos, el poder debía haber planificado la formación de cuadros políticos necesarios para formar a su cargo millones de adherentes» ${ }^{3}$.

En marzo de 1964 se convocaron nuevas elecciones en las que se ponía en práctica por primera vez la exigencia del 50 por 100 de obreros y campesinos en la composición de la Cámara. Esto motivó una nueva distribución del territorio de la República egipcia en 175 circunscripciones de carácter binominal, en las que un escaño, por lo menos, de los dos que cubría cada circunscripción debía corresponder a un obrero o campesino.

Se presentó un total de 1.698 candidatos, y en los resultados finales quedaba claramente reflejado el cambio político nasserista: la mayoría absoluta la tenían los obreros y campesinos, aunque hay que matizar que la naturaleza de los cambios era más formal que real.

Los resultados quedaron de la siguiente forma: 114 campesinos, 75 obreros (52,5 por 100 de campesinos y obreros) y 161 representantes de otras profesiones $(47,5 \text { por } 100)^{4}$.

En 1969, al terminar el período legislativo de la Asamblea, se volvió a renovar la Cámara, manteniendo las mismas disposiciones que en 1964. En esta ocasión fueron presentados 870 candidatos para los 350 escaños. La proporción de campesinos y obreros alcanzó el 50,6 por 100 , y los profesionales, el 49,4 por $100^{5}$.

\section{LA DESNASSERIZACION DEL PRESIDENTE ANUAR AL-SADAT}

En 1970, al morir Nasser, el vicepresidente se hizo cargo de la Presidencia durante sesenta días, período en el que se prepararon los procedimientos previstos por la proclamación constitucional de 1964 para un mandato de seis años: elección por dos tercios, al menos, de la Asamblea y ratificación por

${ }^{3}$ Nada Tomiche, L'Egypte Moderne, París, 1976, p. 91.

4Véase R. H. Dekmejian, "The UAR National Assembly a Pioneering Experiment», Middle East Studies, 4/1968, pp. 361 y ss.

${ }^{5}$ Estos datos han sido extraidos del periódico egipcio Al-Abram del 5 mayo 1984, pp. 3 y 5 . 
referéndum popular. De esta forma, el vicepresidente Anuar al-Sadat fue confirmado como nuevo presidente de la República.

La política iniciada por éste, si bien se decía continuista del carismático raís, va a procurar una progresiva desnasserización de Egipto. Los primeros pasos hacia este nuevo proceso los inició Sadat con lo que ha sido calificado por Ghali Shoukri como el "golpe» del 14 de mayo de $1971^{\circ}$ : la decisión unilateral y por sorpresa del presidente de crear una Federación, que luego no se llevaría a cabo, con Siria y Libia (y la unión posterior de Sudán) provocó la oposición del vicepresidente, Ali Sabri, y de algunos ministros pro nasseristas, circunstancia que es aprovechada por Sadat para ordenar su cese y el del ministro del Interior, punto de arranque de una serie de dimisiones en cadena que permitieron al nuevo rais reorganizar a su favor el aparato estatal, el partido y la Asamblea ?

De esta manera se disolvió la Cámara y se renovó en octubre de ese año, con la participación de 1.522 candidatos, de los cuales el 63,1 por 100 de los elegidos eran obreros y campesinos y el 35,8 por 100 profesionales ${ }^{8}$, sin que de estas cifras y su comparación con las dos últimas elecciones bajo Nasser deba sacarse ninguna conclusión aventurada a propósito de la naturaleza del régimen de Sadat.

En este mismo año se promulga una nueva Constitución, basada en el mismo sistema presidencialista, en que la Asamblea, llamada ahora del Pueblo por deseo de Sadat, elige al presidente por dos tercios de los votos, sometiéndolo después a referéndum. El presidente tiene derecho de veto en los proyectos de ley, pero si el proyecto es votado de nuevo por la mayoría de dos tercios de la Asamblea pasa a ser ley. Todos los miembros pueden dirigir interpelaciones al primer ministro y a los ministros. La Asamblea puede votar una moción de censura contra el primer ministro, pero tiene que someter el informe al presidente, el cual puede devolverlo a la Cámara y, si vuelve a salir aprobado, el presidente debe someter el conflicto a referéndum ${ }^{9}$.

El referéndum popular es el mecanismo político previsto en varias situaciones, y fue frecuentemente utilizado por Sadat como arma de movilización social a favor de su régimen.

En su política de progresiva ruptura con las ideas del socialismo árabe de Nasser, inicia un acercamiento político hacia Occidente, expulsando a los consejeros políticos soviéticos en 1972 y restableciendo relaciones diplomáticas con Washington en 1973. La aproximación a EE. UU. facilita un gradual avance hacia la negociación con Israel, permitiendo en 1975 la utilización del

- Ghali S h oukri, Egypte Contre-Revolution, París, 1979, pp. 47 y ss.

7 Sobre este período, véanse M. H. Heykal, Al-Tariq ila Ramadan, Beirut, 1975 , pp. 117 y ss., y M. Ch. Aulas, «Sadat's Egypt: a Balance Sheet», Merip Reports, julioagosto 1982.

Al-Abram, 5 mayo 1984 , p. 3.

- Véase Bernabé López García y C. Fernández Suzor, Introducción a los regímenes y Constituciones árabes, Madrid, 1985, pp. 181 y ss. 
Canal por este último, asumiendo en 1977 «su derecho a existir dentro de unas fronteras seguras y reconocidas» y negociando directamente «la paz» desde 1978 con el tratado de Camp David.

Unido a esto iba también su proyecto de liberalización económica (infitab) frente a la sociedad cerrada (ingilaq) que, según Sadat, era la egipcia en ese momento. El primer paso fue la ratificación por referéndum, en 1974, de medidas que estimulasen el sector privado en la economía y la intensificación de la inversión extranjera. A continuación, el Parlamento aprobó la Ley número 43 de 1974, destinada a fomentar la inversión de capital extranjero, otorgando a toda nueva empresa, aunque el patrimonio fuese exclusivamente extranjero, diez años de exención tributaria y declarando Port Said puerto franco.

Esta política de liberalización llevó a la inundación del mercado de productos importados, mientras se desmantelaba el sector público, que había constituido el cambio estructural más importante del período nasserista dentro de la economía, y aumentaba la inflación.

Dentro de las coordenadas de liberalización y alineamiento occidental, se hacía necesario dar un aspecto más liberal a la política interior, lo cual llevó a Sadat a afirmar en su Manifiesto de octubre de 1974: «Rechazo el desmoronamiento de la unidad nacional bajo la forma artificial de los partidos, pero tampoco acepto la teoría del partido único que imponga su tutela a las masas.» Para ello ideó una tercera vía que decía aumentar las libertades, pero manteniendo su control: fue la creación de tres plataformas ${ }^{10}$.

Con esto no sólo contribuía a debilitar la USA, sino que desamordazaba también a cierta oposición, satisfaciendo una de sus reivindicaciones. Aprovechaba la apariencia de pluralidad política mientras restauraba a su favor el partido dominante, que era el que tenía el apoyo de la Administración y de las instituciones oficiales.

De esta forma, del tronco común de la USA se desgajaron tres plataformas políticas: una de centro, otra de izquierda y la tercera de derecha.

En primer lugar se formó la plataforma que daría lugar al Partido Socialista Arabe de Egipto (Hizb Misr al-Arabi al-Ichtiraki), que encarnaba la facción pro sadatista, llamada de centro, y cuyo presidente era el primer ministro, Mamduh Salem.

Bajo la plataforma de derecha se situaba lo que sería el Partido Liberal Socialista (Hizb al-Ahrar al-Ichtiraki), cuyo presidente era Mustafa Kamel Murad, perteneciente a la facción derecha de los «Oficiales Libres» de los primeros tiempos de la revolución de julio de $1952^{11}$.

${ }^{10}$ Contradiciendo su concepción del partido expresada en tiempos de Nasser, véase el artículo de Anuar AL-Sadat, «Union National» (traducción de André Miquel), Orient, 7/1958, pp. 157-168.

"Los «Oficiales Libres» fue el grupo de militares que llevó a cabo el golpe de Estado de 1952 y cuya formación venía de 1949, después de la derrota en la guerra de Palestina. 
Y, por último, el Reagrupamiento Nacional Progresista Unitario (AlTayammu al-Watani al-Taqaddumi al-Wahdawi), cuyo líder era otro superviviente de los «Oficiales Libres», dirigente del Consejo de la Revolución, Jaled Muhieddin, constituido como la plataforma de izquierda.

Los dos primeros mantenían una línea neocapitalista y el tercero se situaba en una orientación marxista.

En este marco político se realizaron las elecciones de noviembre de 1976. Los candidatos que se presentaron estaban encuadrados en una de las tres plataformas $o$, fuera de ellas, como independientes. $\mathrm{Y}$ hay que hacer notar que el número de estos últimos fue del 54 por 100 del total, una cifra muy alta si se tiene en cuenta que el presidente opinaba que las propuestas del centro, izquierda y derecha englobaban perfectamente todas las líneas políticas necesarias.

Los resultados electorales dieron la victoria absoluta al denominado centro, que era el gubernamental, con el 80 por 100 de los escaños (280), mientras que los liberales socialistas consiguieron 12, la izquierda 2 y los independientes 49 diputados.

A la plataforma de centro, artífice de los comicios, no le había resultado difícil obtener una aplastante mayoría parlamentaria, siendo como era da única realmente estructurada y que contaba con el apoyo de la Administración y casi el monopolio absoluto de la televisión y la radio.

Por otro lado, la derrota de la izquierda tenía mucho que «agradecer», como ha señalado Pierre Mirel ${ }^{12}$, a los violentos ataques que se le hicieron sobre su ateísmo y a que el pueblo que votaba estaba fuertemente apolitizado tras veinte años de ausencia de participación real en la vida política, y en la que la «opinión» de los agentes del Gobierno era fielmente seguida.

Sin embargo, el éxito, con 49 escaños, de los independientes constituía un interesante reflejo del rechazo a la trilogía política ideada por el raís.

Poco después de estas elecciones, para ofrecer más garantías de liberalismo a los ojos extranjeros $y$, quizá también, para poner fin definitivamente a la USA, acabando así con el símbolo de la época pasada, el presidente acepta, el 11 de noviembre de 1976, la formación de partidos. Pero este paso sufriría al poco tiempo un retroceso, desencadenado por los levantamientos de enero de 1977.

El Fondo Monetario Internacional, ante la situación económica egipcia, exigió la devaluación de la libra egipcia y la reducción drástica de las subvenciones en los artículos de primera necesidad. Cuando el Gobierno anunció estas medidas, el pueblo egipcio se echó a la calle. Se anularon las reducciones de las subvenciones tras recurrir a la ley marcial y a la movilización del Ejército para contener las manifestaciones. El apoyo popular y la legitimidad de Sadat se tambaleaban y decidió enfrentarse a ello empleando una política de «mano dura»: restringió el sistema de partidos, prohibió todo tipo de huelgas,

12 Pierre Mirel, L'Egypte des Ruptures, París, 1982, p. 188. 
sacó una ley de prensa que aseguraba su control por parte del Gobierno y se autorizó al fiscal socialista ${ }^{13}$ a procesar a todo aquel que pusiera en peligro «los logros socialistas» hechos en nombre del pueblo desde 1952.

$\mathrm{La}$ inquietud ante los últimos acontecimientos y el peso de los acuerdos firmados con Israel llevaron al presidente a pensar en la necesidad de una nueva Asamblea adicta a la política exterior del régimen.

De esta manera se convocan nuevas elecciones, tras la disolución de la Cámara, para junio de 1979. El ámbito político había sufrido ciertos cambios con respecto a 1970 .

Aunque Sadat había dado forma legal a la formación de partidos, su giro político de «mano dura» recortó y puso ciertas trabas a su puesta en práctica. A pesar de ello, el partido Neo-Wafd (Wafd al-Yadid) ${ }^{14}$ obtuvo el apoyo necesario para su legalización. Pero el recelo de Sadat hacia este partido, que antes de la revolución nasserista contaba con apoyo popular, le llevó a promulgar una ley que establecía que «todas las personas que hubiesen dominado la vida política antes de 1952 (ministros o miembros de partidos, menos el $\mathrm{Na}$ cional y el Joven Egipto ${ }^{15}$ ) no podían ser miembros de las actuales formaciones políticas». Así fueron muchos los «proscritos», siendo el partido Neo-W afd el que se veía más fuertemente perjudicado, de tal manera que acabó por autodisolverse, no considerando el marco político que brindaba Sadat como el más adecuado para su acción.

Otro partido se formaba en 1978 con el beneplácito del presidente, que lo consideró su «leal oposición»: el Partido Socialista del Trabajo (PST) (Hizh al-Amal al-Ichtiraki). Este partido estaba vinculado al antiguo Joven Egipto (Misr al-Fatat) y fue fundado y liderado por Ibrahim Chukri, diputado gubernamental y ministro de Agricultura de 1977 a 1978. En un primer momento fue un partido dócil que apoyó la política de Camp David, pero evolucionó hacia una postura cada vez más independiente que acabó condenando los acuerdos con Israel y sometiendo a crítica la política del régimen a través de su semanario, $A l$-Chaab, lo que le valió el cierre del periódico y la encarcelación de su director, Helmi Murad, y gran parte de los colaboradores del mismo en septiembre de 1981.

Por otra parte, también en 1978, Sadat decidió crear un partido a su

${ }^{13}$ La Constitución de 1971 había instituido la figura del fiscal socialista (al-Mudda al-Amm al-Ichtiraki), responsable de garantizar los derechos del pueblo, así como para salvaguardar los logros socialistas. Aunque institucionalmente esta figura surgía como «Defensor del Pueblo», acabó cumpliendo las funciones de «Fiscal».

${ }^{14} \mathrm{El}$ Wafd fue el partido dominante y más popular del período monárquico egipcio, que ganó casi todas las elecciones de esta época.

${ }^{15}$ El Partido Nacional fue creado en 1900 por Mustafa Kamel, aunque sus orígenes semiclandestinos se pueden rastrear desde 1879. Fue uno de los partidos que luchó por la independencia durante el dominio británico. El Joven Egipto (Misr al-Fatat) fue un movimiento político que existió de 1929 a 1952, grupo de carácter fascista -más por oposición a los británicos que por una auténtica vocación nacional-socialista- que buscó en las raíces faraónicas la base de un egipcianismo extremista contra las influencias extranjeras. 
imagen y semejanza, el Partido Nacional Democrático (PND) (Hizb al-Watani al-Dimuqrati), desapareciendo la plataforma de «centro» surgida de la USA. Se eligió este nombre para vincularlo con el antiguo partido Nacional de Mustafa Kamel, para hacer sombra al Wafd, que volvía a la escena política.

Seguían existiendo, ahora ya como partidos, el Reagrupamiento Nacional Progresista (RNPU), cuyo semanario, Al-Abali, también fue cerrado en el último período de Sadat, y el Liberal Socialista (PLS), que publicaba el periódico $A l$-Abrar y que nunca vio interrumpida su publicación.

Los resultados de las elecciones dieron al PND 309 diputados $(89,3$ por $100)$; al PST, 29 (7,6 por 100$)$; al PLS, $3(0,8$ por 100$)$, y a los independientes, $9(2,3$ por 100$)$.

En esta ocasión, la izquierda no estaba representada en la Asamblea y los independientes habían perdido su posición de 1976. Sadat controlaba absolutamente la Cámara.

Pero la inestabilidad del régimen y el descontento social se agudizaron progresivamente hasta llegar a 1981, que, marcado por las medidas drásticas y la represión, finalizó con el asesinato del presidente por extremistas musulmanes pertenecientes al grupo Yibad (Guerra Santa).

Las concesiones islamizantes de Sadat ${ }^{16}$, que cayó en la tentación de utilizar y reavivar el sentimiento islámico a favor de su política de supresión sistemática del secularismo de izquierda, sólo consiguieron la reanimación de los disturbios confesionales ante el acoso que sentían los coptos. No consiguieron, sin embargo, detener la cada vez más creciente oposición del fundamentalismo islámico contra el sistema de liberalización económica y los acuerdos con Israel, que llevó a la detención masiva en septiembre de 1981 de los extremistas musulmanes, junto con políticos, intelectuales y personalidades religiosas coptas, y que culminó con el ataque frontal de este fundamentalismo contra todo el sistema en el magnicidio del 6 de octubre de ese mismo año.

\section{LA DESADATIZACION DEL PRESIDENTE MUBARAK}

Cuando el presidente Husni Mubarak accedió a su cargo, la sociedad egipcia se encontraba en estado de crispación y el descontento parecía generalizado. Con un país en estado de emergencia y una oposición cada vez más fuerte al régimen de Sadat por su corrupción y falta de libertades, el nuevo presidente optó por la toma de una serie de medidas que volvieran a dar crédito a las instituciones y al régimen. Para ello inició, aunque con gran prudencia, un proceso de desadatización en su política interior, caracterizado sobre todo por el aumento de las libertades públicas y de prensa.

16 Sadat, desde la Constitución de 1971 , en que quedó establecido que «los principios de la Ley Islámica constituyen una fuente principal de legislación», quiso jugar la baza del reforzamiento del Islam llevando a cabo una cierta «retradicionalización». 
Las primeras medidas dentro de estos objetivos fueron la puesta en libertad de la mayoría de los detenidos políticos y el comienzo de una campaña anticorrupción, ya que el enriquecimiento por corrupción en los medios locales de negocios se había convertido en una práctica demasiado común en los últimos tiempos de Sadat, con su política de liberalización para atraer las inversiones extranjeras. La ineficacia burocrática y la organización de la economía, en un sistema donde los contactos a determinado nivel eran imprescindibles para conseguir un contrato o franquear una aduana, favorecían estos círculos de corrupción.

En la campaña anticorrupción ahora iniciada se enmarcó el juicio al hermano de Sadat, Esmat al-Sadat. En febrero de 1983, el Tribunal de Etica le condenó a un año de detención preventiva y al secuestro judicial de los bienes y propiedades de la familia ${ }^{17}$. Además, en las investigaciones que se llevaron a cabo para el juicio se señaló la participación y responsabilidad en actos de corrupción y tráfico de influencia de dos ministros, tres ex ministros y unos veinte directores del sector público. Esto llevó al presidente a la destitución de los dos ministros, Ahmad Nuh e Ibrahim Abu Zagla, anunciando también el cambio de algunos gobernadores provinciales.

Otro juicio que también sirvió para reforzar la imagen de desadatización que deseaba proyectar Mubarak, demostrando el funcionamiento ecuánime de las instituciones del Estado, fue el de los trescientos fundamentalistas islámicos a los que se les acusaba del asesinato de Sadat, de la tentativa de derrocamiento del régimen por la fuerza y de los disturbios que siguieron en la ciudad de Assiut ${ }^{18}$. El juicio se inició el 4 de diciembre de 1982, y dentro de la evolución democratizadora se enmarcó la denuncia de los acusados de las fuertes torturas a las que habian sido sometidos.

La libertad de prensa también se vio positivamente afectada por la nueva situación $\mathrm{y}$, así, los órganos de prensa de los partidos de la oposición que habían sido prohibidos en el período anterior volvieron a ser publicados, como fue el caso del periódico del RNPU, Al-Abali, y del PST, Al-Chaab, que reaparecieron a partir de mayo de 1982 .

Estas iniciativas del nuevo presidente fueron vistas con alivio y esperanza, apoyándolas todos los partidos legales de la oposición y la opinión pública en general, ya que confirmaban el rumbo aperturista de Mubarak.

Sin embargo, este proceso que, evidentemente, quiso iniciar Mubarak desde que ocupó la Presidencia fue siempre llevado con precaución y cautela, quizá por ser consciente de que poner excesivamente en entredicho todo el sistema y la figura de Sadat podría hacer cuestionar también su propia legiti-

17 Al-Abram, 14 febrero 1983 , pp. 1 y 3.

18 El día 8 de octubre, dos días después del asesinato de Sadat, un comando de fundamentalistas tomó militarmente los puntos neurálgicos de la ciudad de Assiut. Varios días después, el Ejército logró controlar la situación. Esta ciudad es un centro de integrismo que ya presenció disturbios anteriores, especialmente durante 1980. 
midad, ya que él le había sucedido por haber sido elegido vicepresidente por su predecesor.

En este sentido, cuando aumentó el ensañamiento contra el anterior presidente por parte de algunos órganos de prensa de la oposición, se tomaron una serie de medidas restrictivas que incluso llevaron a esa misma oposición a hablar de una cierta «marcha atrás». Las críticas venían por la «Ley de Secretos de Estado», aprobada en mayo de 1983, y que desató una fuerte polémica y una unánime denuncia por parte de la oposición. Según esta Ley, «se impide por un plazo de veinte años la publicación de cualquier tipo de investigación sobre información confidencial relativa a personalidades políticas y acontecimientos históricos recientes, bajo pena de prisión de tres a cinco años».

En esta misma línea de cautela del presidente Mubarak, en agosto del mismo año, el Tribunal de Etica dispuso el levantamiento de la detención preventiva a la que en febrero del mismo año había sido condenado el hermano de Sadat, aunque el secuestro judicial de los bienes y propiedades de la familia se mantuvo. Se subrayaba en esta misma decisión del Tribunal la integridad del anterior presidente. «Sólo los individuos son responsables de sus actos», afirmaba la sentencia ${ }^{19}$.

Motivo de protesta fue también la prórroga del estado de emergencia, que autorizaba detenciones sin juicio, durante un plazo de seis meses. La Ley de Excepción se conservaba desde el 6 de octubre de 1981, en que fue asesinado Sadat, renovándose en octubre de 1982 «ante la persistencia de la amenaza terrorista en el país», según informaban las fuentes gubernamentales. En octubre de 1983 se prolongó un año más, ya que el Gobierno lo consideraba vital para mantener la seguridad y estabilidad nacionales, según informó el ministro del Interior, Hasan Abu Bacha, en una entrevista al periódico Al-Abram ${ }^{20}$, justificándolo por la detención de 45 miembros del Partido de Liberación Islámica (Hizb al-Tahrir al-Islami) y de militantes comunistas y por estar aún pendiente el juicio de los extremistas musulmanes, para los cuales el fiscal pedía casi trescientas penas de muerte.

La oposición consideraba que el mantenimiento del estado de excepción podía tener efectos adversos sobre el clima electoral de los comicios legislativos que estaba previsto realizar entre abril y mayo del siguiente año y, por supuesto, también sobre sus resultados.

La evolución democratizadora afectó también a los partidos políticos. En julio de 1983, por una decisión del Consejo de Estado, el Partido de la Umma era legalizado. Este hecho es importante desde dos puntos de vista. Primero, porque es la primera vez que un partido político logra su autorización por una decisión del poder judicial. A este partido le había rechazado su legalización en 1979 el Comité Gubernamental de los Partidos Políticos, y es el

19 Al-Abram, 2 agosto 1983 , pp. 1 y 5.

${ }^{20}$ Al-Abram, 3 octubre 1983, p. 6. 
Consejo de Estado quien ahora invalida esa decisión. El segundo punto a tener en cuenta es que se trata de un partido de orientación islámica y que su meta es luchar por la aplicación total de la Charia o ley islámica en Egipto, aunque no se define como partido religioso, ya que en este país está prohibida la formación de partidos de ese tipo. La razón de su legalización podría verse en el deseo de incluir en el juego institucional una opción islámica moderada que sirviese para aislar a los grupos más radicales, frente a la gran masa de devotos musulmanes que suponen una fuerza muy importante $y$ una mayoría social en el país.

Por otra parte, surgió un contencioso legal con respecto al partido NeoWafd, que aparecería como posible competidor del PND. El Neo-Wafd se había autodisuelto en 1978 y cuando, en 1983, decidió volver a la vida política, la Comisión de los Partidos le consideró inexistente por haberse retirado voluntariamente de la vida política nacional hacía cinco años. Al Consejo de Estado le cupo dictar una nueva sentencia en que se reconocía la existencia legal de este partido. El Gobierno remitió su objeción a esta sentencia, pero dicha objeción no presentaba bases jurídicas suficientemente sostenibles y el Neo-Wafd quedó legalizado, y Fuad Sarag al-Din, representante de la clase terrateniente que había dominado la escena política egipcia antes de la revolución y antiguo secretario general del $W$ afd, pasó a serlo también ahora del Neo-Wafd, tras la abolición de la ley de Sadat que le impedía participar en la actividad política.

Todo este proceso apuntaba hacia la intención de realizar las legislativas con una limpieza y garantías inusuales en anteriores comicios y hacia la credibilidad en la independencia del poder judicial, a pesar de lo incómodo que le resultaba al partido gubernamental la existencia del $W$ afd.

\section{LAS ELECCIONES LEGISLATIVAS DEL 27 DE MAYO DE 1984}

La nueva Ley Electoral de $1983^{21}$

La Ley número 114 de 1983 supuso una gran reforma de la Ley Electoral hasta entonces vigente en Egipto. Estos cambios se incluyeron dentro del avance democrático y fueron dirigidos hacia un aumento del pluralismo político y una mayor competitividad en los comicios. Aunque aún subsisten ciertas trabas en esta Ley que deslucen la apertura democrática, hay que reconocer que aportó aspectos muy positivos con respecto a períodos anteriores, ampliando las posibilidades para los partidos de la oposición de acceder a la Cámara.

Por primera vez en la historia de Egipto se cambiaba el sistema electoral

${ }^{21}$ El texto completo de esta Ley fue publicado por el Ministerio de Información en Al-Intijabat. Al-Dimuqratiya fi Misr. Taymi Tawdiqi, El Cairo, 1984, pp. 16-53. 
de mayoría absoluta por el sistema proporcional, y el proceso de candidaturas individuales, por el de listas de partidos, desapareciendo la posibilidad de candidaturas independientes.

$\mathrm{Al}$ elector se le presentan listas cerradas de los diferentes partidos que concurren y sólo puede optar por una de ellas tal y como se le presenta, sin poder realizar ningún cambio en el orden de los candidatos. Este orden debe alternar en la lista a un candidato profesional con otro obrero o campesino, asegurando de esta forma el requerimiento de la Ley, que exige que el 50 por 100 de los miembros de la Asamblea sean obreros y campesinos 22

Dentro del sistema proporcional, para tener derecho a estar representados en la Asamblea del Pueblo, los partidos deben obtener un mínimo del 8 por 100 de los votos a nivel nacional. Los votos del partido o partidos que no lo consigan pasan al que haya obtenido el mayor número de éstos. Evidentemente, esta condición del 8 por 100 supone una traba para la competitividad de de los comicios y, de hecho, fue el aspecto más polémico del nuevo sistema electoral. Es más, en un principio, el porcentaje se estableció en un 10 por $100 \mathrm{y}$, ante la amenaza por parte de la oposición de boicotear las elecciones, el presidente Mubarak solicitó a la Asamblea que lo redujera a un 8 por 100 .

De los 340 escaños que tenía la Asamblea anterior se amplió a 448, de los cuales se fijó que 31 estaban reservados a la mujer ${ }^{23}$. El carácter obligatorio de cubrir estos escaños femeninos impone a los partidos que presenten listas en las elecciones un mecanismo especial: en las 31 circunscripciones donde existe este escaño tienen que presentar una candidata al final de la lista de los candidatos numerados, y el partido que consigue el mayor número de votos en esa circunscripción es el que obtiene el escaño de la mujer para la Asamblea.

El nuevo sistema obligó, a su vez, a la redistribución geográfica y numérica de las 26 provincias que forman la República Arabe de Egipto (ya que no era válida la división anterior en 175 por su carácter binominal), que quedaron divididas en 48 circunscripciones. Exigiendo, por otra parte, una reelaboración general en la presentación de candidaturas, mecanismos de voto y escrutinio, con la creación de diferentes comisiones para supervisar todos los aspectos electorales.

22 Esta condición, desde que quedó establecida en la proclamación constitucional de 1964 , se ha mantenido exactamente igual hasta hoy día, siendo el más claro vínculo que ha interesado mantener del período naserista, como símbolo de la «democracia social».

${ }^{23}$ Hasta 1979, el número de mujeres en la Asamblea fue de cuatro; pero, en este año, Sadat, en un momento de ciertos avances para la mujer gracias a la ley del «estatuto personal», inspirada por la mujer del presidente, éste decidió ampliar el número de mujeres en la Asamblea a treinta. 
División por provincias de la $R A E$

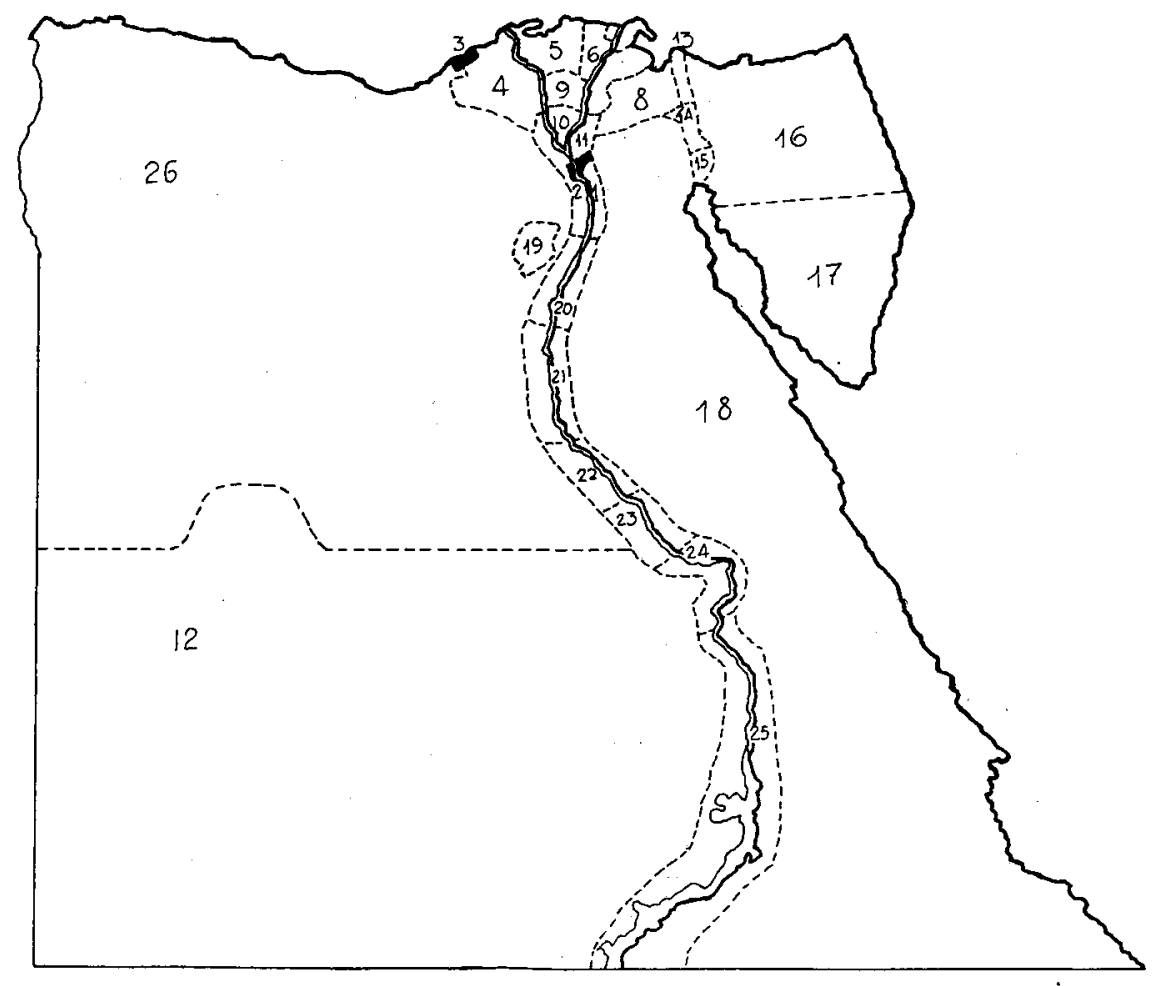

1. El Cairo

2. Giza

3. Alejandría

4. Buhayra

5. Kafr al-Chayj

6. Daqahliyya

7. Damieta

8. Charqiyya

9. Garbiyya

10. Manufiyya

11. Qalyubiyya

12. Wadi al-Yadid

13. Port Said
14. Ismailiyya

15. Suez

16. Sinaí Norte

17. Sinaí Sur

18. Mar Rojo

19. Al-Fayum

20. Beni Suef

21. Al-Minya

22. Assiut

23. Suhay

24. Qena

25. Aswan

26. Marsa Matruh 


\section{Partidos y coaliciones ante las elecciones}

El enorme interés que ofrecen estas elecciones no es sólo por la aplicación de un nuevo sistema electoral, ni por la ampliación del juego político en el que compiten diferentes partidos, sino también por lo que significa la participación del $W$ afd, que había sido el gran partido nacionalista, laico y liberal surgido de la revolución de $1919^{24}$.

Las elecciones probarían si las altas cotas de popularidad que poseía en el régimen anterior habían resistido los treinta años de ausencia, durante los cuales tanto Nasser como Sadat hicieron todo lo posible para extirparlo de la memoria de los egipcios, gran parte de los cuales no ha vivido los años anteriores a la revolución.

Ante este reto y para ayudar a garantizar el éxito, los wafdistas presentaron una oferta electoral muy ambiciosa, en la que la gran novedad era la fórmula de alianza con los Hermanos Musulmanes, también existentes antes de $1952^{25}$. Este partido, el Wafd, a pesar de su componente electoral copto, su carácter laico y su antagonismo con los Hermanos Musulmanes en el período monárquico, quiso hacer converger estos intereses para atraerse los votos integristas, que suponían un elemento importante en el juego electoral. Aunque el tema de la aplicación de la ley islámica, objetivo fundamental de los Hermanos, presuponía el rechazo categórico de la minoría copta, el Wafd confiaba en mantener a esta minoría cristiana a su favor en contra del partido gubernamental, que mantenía aún bajo arresto, en un monasterio de Wadi Natrún, al patriarca de esta Iglesia, Chenuda III ${ }^{26}$.

La tolerancia por parte del poder de esta polémica alianza con los todavía ilegales Hermanos Musulmanes, aunque fue muy criticada y considerada «contra natura» por el PND por evidentes motivos electoralistas, no deja de poner de relieve la intención del presidente Mubarak de tratar de integrar en el juego democrático e institucional la tan importante corriente islámica

24 El malestar por la presencia inglesa en Egipto se agravó al estallar la Primera Guerra Mundial, por sus consecuencias económicas, y acabó con el estallido revolucionario de 1919, del que tomó las riendas el partido Wafd, recién creado, y cuya más directa consecuencia fue la concesión de la independencia en 1922.

${ }^{25}$ Creados en 1928 por Hasan al-Banna, los Hermanos Musulmanes pedían la islamización absoluta del país y la lucha contra la occidentalización, criticando con violencia el régimen parlamentario dominado por el $W$ afd. Alcanzaron su mayor auge durante la Segunda Guerra Mundial y, especialmente, por su lucha en la guerra de 1948 contra los sionistas. Sus contactos con los «Oficiales Libres» les valió en un primer momento seguir siendo el único partido autorizado tras 1952 , pero su relación con el régimen se fue enrareciendo hasta que acabaron definitivamente disueltos y perseguidos después de que un hermano musulmán intentase asesinar a Nasser en 1954.

${ }^{26}$ Sadat, en septiembre de 1981, dentro de la gran represión que llevó a cabo, destituyó y confinó en un monasterio al Papa de la Iglesia copta, Chenuda III, y nombró un Consejo papal para sustituirle. En enero de 1983, Mubarak anuló dicho Consejo, pero no permitió la restitución de Chenuda, estipulando la elección de un nuevo Papa. El proceso concluyó con la liberación y restitución de Chenuda III como Papa a finales de 1984. 
de la sociedad egipcia, para intentar aislar a los grupos más violentamente militantes del Islam actual. Esta cobertura podía haberla ofrecido el partido de la Umma, pero éste anunció que no se presentaría a las elecciones por escasez de fondos y falta de suficientes candidatos que presentar.

Además del $W$ afd y el partido gubernamental, $P N D$, participaron en los comicios todos los partidos, a excepción del de la Umma, que desde la decisión de Sadat de acabar con el sistema unipartidista fueron formándose y obteniendo su legalización: PLS, RNPU y PST.

Todos ellos tenían que elegir un símbolo que les representase en todo el proceso electoral y que recibiese el visto bueno del ministro del Interior. El Wafd quiso elegir el antiguo símbolo monárquico, que consistía en una media luna con tres estrellas, pero se le rechazó esta posibilidad (aunque, de hecho, lo utilizó en algunos carteles durante la campaña) y eligió una palmera; el $P N D$ se identificó con la media luna; el PST, con una estrella de cinco puntas; el RNPU, con un reloj, y el PLS, con una llave.

\section{La campaña y los programas electorales}

La campaña electoral, que comenzó el 23 de abril y quedó cerrada el 25 de mayo, se caracterizó por su gran actividad, debido básicamente al aumento de la competitividad entre los diferentes partidos y al enorme número de candidatos que existían.

Todos los partidos de la oposición disponían de su órgano de prensa, a través de los cuales se llevó a cabo una intensa campaña sin sufrir ningún tipo de censura: el RNPU, su semanario Al-Abali; el PST, el también semanario $A l$-Chaab; el $P L S, A l$-Abrar, y el Wafd, que desde su definitiva inserción en la actividad política empezó a publicar, en marzo de 1984, un periódico de carácter semanal llamado también Wafd.

En cuanto a los medios de comunicación estatales como lo son la radio y la televisión, por primera vez todos los partidos tuvieron acceso a ellos para exponer $y$ defender sus programas respectivos.

El partido gubernamental dedicó una parte de sus esfuerzos en la campaña a luchar contra la abstención, que podía deslegitimar su intento democrático, y otra a su lucha contra el $W$ afd, que se perfilaba claramente como su verdadero competidor en la contienda. Por su parte, el Wafd se dedicó al desprestigio continuo del PND, a la recuperación de sus antiguos votantes y a la captación de la nueva opción islámica.

En el enfrentamiento entre el $P N D$ y el $W$ afd , el elemento nacionalista desempeñó un papel muy destacado, disputándose ambos partidos las esencias del nacionalismo egipcio como herederos, el primero, de la revolución de 1952, que consiguió todos los logros socialistas para los trabajadores y campesinos, 
acusando al Wafd de su carácter antirrevolucionario y colaboracionista en el antiguo régimen ${ }^{27}$, y, el segundo, de la revolución de 1919.

Por su parte, el Wafd se defendía del antirrevolucionarismo que le achacaban afirmando, a través de su periódico: «El Wafd nunca ha sido contrario a la revolución y no tiene intención de suprimir treinta años de la historia ni abrir los dossieres del pasado. Tampoco existe espíritu de venganza en él contra los hijos de la revolución de julio, pues no desea que la unidad de Egipto dé un paso atrás» ${ }^{28}$.

También competían por el protagonismo político en el quehacer democrático. El PND, como se ha dicho, se presentaba como el paladín del cambio democrático, permitiendo la libertad de expresión real y el verdadero pluripartidismo para unas elecciones libres. Sin embargo, el Wafd defendía que el indudable espíritu democrático era el suyo, demostrado a lo largo de diez elecciones celebradas antes de 1952.

El RNPU competía con el PND por la herencia socialista de la revolución de 1952, publicando en su periódico una entrevista con el hijo mayor de Nasser, Jaled Abdel Nasser, en la que afirmaba que el partido gubernamental no representaba a esta revolución ${ }^{29}$. Al Wafd lo presentaba como un partido reaccionario al que le reconocía que en su momento fue un partido ganador y popular, pero carente de vigencia en la sociedad egipcia del momento por la evolución que ésta había sufrido desde 1952.

El PLS fue ignorado por los otros partidos, y hasta él mismo llevó una campaña menos activa, quizá siendo consciente de sus pocas posibilidades de éxito.

El PST, menos definido ideológicamente, aunque presentó un gran número de candidatos y dedicó su campaña a atacar al Wafd y al PND, no obtuvo apenas respuesta por parte de ambos, dedicados a competir entre sí.

Otro nuevo elemento que apareció a lo largo de la campaña y en los programas electorales fue la referencia continua de los partidos a la época anterior a 1952, hasta entonces ignorada en el juego político. Se debía, por un lado, a la participación por primera vez de dos fuerzas políticas existentes en ese período, el Wafd y los Hermanos Musulmanes, y, por otro, al intento de huir de la catalogación que les había dado Sadat a ciertos partidos («izquierda», «derecha», «leal oposición») que les llevó a insistir en su identificación con los movimientos históticos que los compusieron, existentes en la Monarquía y luchadores contra el dominio británico.

Entre los programas electorales de los cinco partidos que se presentaban, el más radical era el del RNPU, de ideología básicamente marxista y nacionalista. Se oponía tajantemente al sistema económico de liberalización, al que

${ }_{27}$ Al-Ajbar, 5 mayo 1984, p. 12; Ajbar al-Yawm, 19 mayo 1984, p. 12, y Al-Abram, 25 mayo 1984 , pp. 1 y 7.

${ }^{28} A l$-W afd, 3 mayo 1984, p. 1.

${ }^{29}$ Al-Abali, 9 mayo 1984, p. 1. 
hace responsable de «haber extendido la corrupción, haber hundido la industria nacional y bloqueado el sector público, favoreciendo la explotación de las masas y la desigualdad social» ${ }^{30}$. A cambio proponía el control absoluto de la inversión extranjera y la detención de la apertura consumista que invade al país, potenciando el desarrollo y la protección del sector público. Se oponía radicalmente al acuerdo de Camp David y a las relaciones privilegiadas con EE. UU., apoyando el acercamiento hacia los países socialistas, pero siendo partidario de mantener a Egipto en el no alineamiento. Defendía la realización de una reforma constitucional que recortase los poderes del presidente y fuese su elección directa, general y entre todos los candidatos que se quisieran presentar.

El partido Wafd se presentaba como una plataforma abierta a todas las tendencias, desde los Hermanos Musulmanes a la comunidad copta. En el aspecto económico, era partidario de una economía mixta eficiente y justa, con más libre competencia, menos monopolio y un equilibrio entre el sector público y el privado, con una justicia distributiva basada en unos impuestos estables y equitativos. También defendía una corrección parlamentaria del actual sistema presidencial, exigiendo, al igual que todos los partidos de la oposición, el levantamiento de la Ley de Excepción. En política exterior afirmaba que «aunque fue partidario del acuerdo de Camp David, ante la violación de éste por parte israelí atacando la central nuclear iraquí, invadiendo Líbano y extendiendo sus colonias en territorio ocupado palestino, no cabe más alternativa que considerar que el tratado ha dejado de ser válido en sus bases iniciales» ${ }^{31}$. Como línea a seguir en política exterior se mostraba partidario del neutralismo y el no alineamiento.

El PLS apoyaba la acción económica basada en la liberalización, e incluso proponía el incremento del sector privado para equilibrarlo con el público gradualmente. En cuanto a Camp David, no sólo defendía su vigencia, sino que reivindicaba como propia la iniciativa de dicho acuerdo: «el PLS fue el primer partido que propuso la conveniencia de la negociación directa con Israel en 1976, antes de que Sadat la llevase a cabo. Por ello seguimos apoyando la política de paz como la mejor solución» ${ }^{32}$.

El PST proponía la rectificación del liberalismo económico para que se abandonase la orientación consumista y se diversificasen los intercambios comerciales, no dirigiéndolos prioritariamente hacia los países occidentales. Defendía también la planificación y desarrollo del sector público, eliminando las empresas deficitarias. Paradójicamente, fue el partido que propugnó medidas de islamización más radicales. Aun cuando en un principio vio con buenos ojos Camp David, como se señaló anteriormente, proponía un bloqueo

${ }^{30}$ Los programas electorales de los partidos fueron publicados por la revista Al-Talia, reaparecida tras su suspensión en la época de Sadat, en el número de mayo de 1984. Op. cit., p. 108, apartado "Ayyuha al-Ijwa wa al-Ajwat».

${ }^{31}$ Op. cit., p. 128 , apartado "Muahada al-Salam maa Misr".

32 B. AL-Din HaSAN, Abaad al-Luba al-Intijabiyya, El Cairo, 1984, p. 169. 
del mismo y un boicot absoluto de cualquier presencia económica o cultural israelí en Egipto. Su visión del no alineamiento en política exterior es interpretada a través de unas relaciones equilibradas entre Oriente y Occidente.

Finalmente, el PND, cuyo líder es el presidente Mubarak y secretario general el primer ministro, centró su programa electoral en el desarrollo de su política de infitah, aunque introduciendo el matiz de «apertura productiva» para intentar corregir las desviaciones de la corrupción y el consumismo que el sistema heredado de Sadat había generado. En esta línea proponía la revitalización del sector público en eficacia, no en extensión. Defendía la apertura política con elecciones y prensa libres y, en política exterior, una solución política global del conflicto de Oriente Medio, reparando la ruptura con el mundo árabe y defendiendo el no alineamiento.

\section{Las candidaturas}

Podemos afirmar que las elecciones de 1984 fueron mucho más concurridas que las anteriormente realizadas en Egipto. El aumento del número de escaños, la exigencia de la Ley Electoral de presentar un suplente por cada candidato (aunque, de hecho, esto no se cumplió) y la conveniencia de cubrir con candidatos la mayoría de las circunscripciones para poder alcanzar el 8 por 100 de votos a nivel nacional, influyeron enormemente en esta circunstancia.

Entre los cinco partidos que se presentaron, el número total de candidatos fue de 2.016, más los suplentes. El PND se presentó en las 48 circunscripciones con 448 candidatos, dándose el caso de que en una de ellas, Sinaí Sur, se presentó solo. Estuvo seguido por el PST, que presentó listas en 46, que contabilizaban 436 candidatos. El W afd presentó 422 candidatos repartidos en 44 circunscripciones, estando ausente en las cuatro menos pobladas provincias desérticas: Mar Rojo, Wadi al-Yadid, Marsa Matruh y Sinaí Sur, que eran las que ofrecían el menor número de escaños y donde la realización de la campaña electoral suponía muchas dificultades en tan vasto territorio. El RNPU, con 412 candidatos, faltó en cinco circunscripciones: Ismailiyya, Suhag, Mar Rojo y la citada Sinaí Sur. EI PLS fue el partido que menos circunscripciones cubrió, con una diferencia notable con respecto a los demás: 278 candidatos para 28 circunscripciones, lo que supuso estar ausente en veinte, algunas de ellas de singular importancia como Giza, El Cairo o Assiut ${ }^{33}$.

Menos en el caso de este último partido, se observa que las circunscripciones del delta, en su totalidad, y del valle del Nilo, casi en su totalidad, estuvieron cubiertas por listas de todos los partidos, siendo éstas las que ofrecían el mayor número de electores. Este hecho permite pensar en que la difi-

${ }^{33}$ Todos los datos fueron publicados en Al-Abram y Al-Ajbar del 30 mayo 1984. 
cultad para ciertos partidos de encontrar candidatos les llevó a permanecer ausentes de la contienda electoral en algunas provincias.

El análisis de las candidaturas permite detectar ciertas novedades con respecto a elecciones anteriores. Por una parte, en lo que respecta a la edad de los candidatos, hay que señalar que los jóvenes han tenido mayor participación en las listas y que fue éste un factor bastante potenciado por los partidos, especialmente por el RNPU. Por otro lado, el número de candidatos que se presentaban por primera vez fue muy elevado y tuvo mucho eco en la prensa de los respectivos partidos. Esta circunstancia estuvo facilitada por la participación de un «nuevo» partido, el $W$ afd, que inevitablemente presentaba un gran número de nuevos rostros en el panorama político, y por el interés del PND de presentar figuras nuevas (en El Cairo, de 44 candidatos, 33 eran nuevos) que ayudasen a romper la continuidad con la época anterior, diesen más credibilidad al nuevo período democrático y asegurasen una mayoría cercana al presidente. Por este motivo, el PND retiró de las listas a ciertas personalidades del círculo interno de Sadat $y$, de hecho, no aparecieron 197 diputados que formaban parte de la Asamblea vigente, entre ellos algunos ministros, como el de Defensa y el de Exteriores ${ }^{34}$. De cualquier forma, esta circunstancia no impedía que siguiesen siendo ministros, ya que no existe la obligación constitucional de que los miembros del Gobierno sean, a su vez, del Parlamento. El nombramiento de ministros es competencia directa y exclusiva del presidente, no necesitando para ello autorización parlamentaria.

Es necesario también detenerse en los elementos sociológicos extrínsecos a la ideología o programa electoral que los partidos políticos conjugan a la hora de presentar a sus candidatos, y que juegan un importante papel para atraer el voto.

Estos elementos en ocasiones son definitivos a la hora de elegir, ya que en un país como Egipto, que no ha conocido un sistema pluripartidista desde hace más de treinta años y donde la apolitización y el clientelismo hacen estragos, especialmente entre la población rural, los factores de popularidad y simpatía rigen más que la orientación política del candidato al que se vota.

Por ello, en las candidaturas se introdujeron factores territoriales (ser «hijo de la circunscripción» hacía inclinar la balanza hacia un lado u otro) y religiosos (se tuvo muy en cuenta las zonas de mayoría poblacional copta, para introducir candidatos de esta religión, o, por el contrario, zonas tradicionalmente conocidas por sus tendencias fuertemente islámicas tenían, como candidatos del Wafd, Hermanos Musulmanes en virtud a su coalición). Esto motivó también la ausencia de algún partido, como pudiera ser el caso del $R N P U$ en Ismailiyya, ciudad fundacional de los Hermanos Musulmanes y donde aquel partido no se presentó dado su carácter laico y los reproches de «ateísmo» que se le imputaban.

${ }^{34}$ Al-Abali, 25 abril 1984, p. 1. 
Las candidaturas de los partidos

\begin{tabular}{|c|c|c|c|c|c|}
\hline Provincias & $\begin{array}{l}\text { Circunscrip- } \\
\text { ciones }\end{array}$ & Sedes & $\begin{array}{l}\text { Esca- } \\
\text { ños }\end{array}$ & $\begin{array}{l}\text { Muje- } \\
\text { res }\end{array}$ & Partidos \\
\hline \multirow[t]{5}{*}{ El Cairo } & 1.' Norte & Chubra & 12 & * & $\begin{array}{l}\text { PND, PST, Wafd, } \\
\text { RNPU, PLS }\end{array}$ \\
\hline & 2." Sur & Viejo Cairo & 10 & * & $\begin{array}{l}\text { PND, PST, Wafd, } \\
\text { RNPU, PLS }\end{array}$ \\
\hline & 3.* Este & Misr al-Yadid & 12 & * & $\begin{array}{l}\text { PND, PST, Wafd, } \\
\text { RNPU }\end{array}$ \\
\hline & $4 .^{a}$ Oeste & Sayyida Zinab & 10 & * & $\begin{array}{l}\text { PND, PST, Wafd, } \\
\text { RNPU, PLS }\end{array}$ \\
\hline & 5." Centro & Bad al-Chariyya & 10 & $*$ & $\begin{array}{l}\text { PND, PST, Wafd, } \\
\text { RNPU, PLS }\end{array}$ \\
\hline \multirow[t]{3}{*}{ Alejandría } & 1. Este & Al-Muntaza & 10 & * & \multirow{3}{*}{$\begin{array}{l}\text { PND, PST, Wafd, } \\
\text { RNPU, PLS } \\
\text { PND, PST, Wafd, } \\
\text { RNPU, PLS } \\
\text { PND, PST, Wafd, } \\
\text { RNPU, PLS }\end{array}$} \\
\hline & 2." Centro & Bab Charqi & 8 & * & \\
\hline & 3. ${ }^{a}$ Oeste & Karmuz & 8 & & \\
\hline Port Said & 1 & Port Said & 6 & * & $\begin{array}{l}\text { PND, PST, Wafd, } \\
\text { RNPU, PLS }\end{array}$ \\
\hline Suez & 1 & Suez & 4 & * & $\begin{array}{l}\text { PND, PST, Wafd, } \\
\text { RNPU, PLS }\end{array}$ \\
\hline Damieta & 1 & Damieta & 8 & * & $\begin{array}{l}\text { PND, PST, Wafd, } \\
\text { RNPU, PLS }\end{array}$ \\
\hline Ismailiyya & 1 & Ismailiyya & 6 & * & PND, PST, Wafd \\
\hline \multirow[t]{3}{*}{ Giza } & 1. & Giza & 10 & * & $\begin{array}{l}\text { PND, PST, Wafd, } \\
\text { RNPU, PLS }\end{array}$ \\
\hline & $2 .^{\mathrm{a}}$ & Imbaba & 10 & & $\begin{array}{l}\text { PND, PST, Wafd, } \\
\text { RNPU }\end{array}$ \\
\hline & $3 .^{*}$ & Huwamdiyya & 6 & & $\begin{array}{l}\text { PND, PST, Wafd, } \\
\text { RNPU }\end{array}$ \\
\hline Beni Suef & 1 & Beni Suef & 14 & * & $\begin{array}{l}\text { PND, PST, Wafd, } \\
\text { RNPU, PLS }\end{array}$ \\
\hline Al-Fayum & 1 & Al-Fayum & 14 & * & $\begin{array}{l}\text { PND, PST, Wafd, } \\
\text { RNPU, PLS }\end{array}$ \\
\hline \multirow[t]{2}{*}{ Al-Minya } & $1 .^{2}$ & Al-Minya & 14 & * & $\begin{array}{l}\text { PND, PST, Wafd, } \\
\text { RNPU, PIS }\end{array}$ \\
\hline & $2 .^{2}$ & Samalut & 10 & & $\begin{array}{l}\text { PND, PST, Wafd, } \\
\text { RNPU }\end{array}$ \\
\hline Assiut & $\begin{array}{l}1 . \\
2 .\end{array}$ & $\begin{array}{l}\text { Awwal Assiut } \\
\text { Abu Tiy }\end{array}$ & $\begin{array}{r}12 \\
8\end{array}$ & $*$ & $\begin{array}{l}\text { PND, PST, Wafd } \\
\text { PND, PST, Wafd, } \\
\text { RNPU }\end{array}$ \\
\hline
\end{tabular}

* Circunscripciones con escaño reservado para la mujer. 
Las candidaturas de los partidos (Continuación)

\begin{tabular}{|c|c|c|c|c|c|}
\hline Provincias & $\begin{array}{l}\text { Circunscrip- } \\
\text { ciones }\end{array}$ & Sedes & $\begin{array}{c}\text { Esca- } \\
\tilde{n} o s\end{array}$ & $\begin{array}{l}\text { Muje- } \\
\text { res }\end{array}$ & Partidos \\
\hline \multirow[t]{2}{*}{ Suhay } & $1 .^{a}$ & Bandar Suhay & 14 & * & $\begin{array}{l}\text { PND, PST, Wafd, } \\
\text { RNPU, PLS }\end{array}$ \\
\hline & $2 .^{2}$ & Ajmim & 10 & & $\underset{\text { PLS }}{\text { PND, PST, Wafd, }}$ \\
\hline \multirow[t]{2}{*}{ Qena } & 1.' Sur & Qena & 14 & * & $\begin{array}{l}\text { PND, PST, Wafd, } \\
\text { RNPU }\end{array}$ \\
\hline & 2." Norte & Nay Hammadi & 8 & & $\begin{array}{l}\text { PND, PST, Wafd, } \\
\text { RNPU }\end{array}$ \\
\hline Aswan & 1 & Aswan & 8 & * & $\begin{array}{l}\text { PND, PST, Wafd, } \\
\text { RNPU, PLS }\end{array}$ \\
\hline Mar Rojo & 1 & Mar Rojo & 4 & * & PND, PST \\
\hline \multirow[t]{3}{*}{ Daqahliyya } & 1. & Awwal Mansura & 12 & * & $\begin{array}{l}\text { PND, PST, Wafd, } \\
\text { RNPU, PLS }\end{array}$ \\
\hline & $2 .^{2}$ & Mit Gamr & 10 & & $\begin{array}{l}\text { PND, PST, Wafd, } \\
\text { RNPU, PLS }\end{array}$ \\
\hline & $3 .^{\mathrm{a}}$ & Dikirnis & 10 & & $\begin{array}{l}\text { PND, PST, Wafd, } \\
\text { RNPU, PLS }\end{array}$ \\
\hline \multirow[t]{3}{*}{ Sarqiyya } & $1 .^{a}$ & Zaqaziq & 12 & * & $\begin{array}{l}\text { PND, PST, Wafd, } \\
\text { RNPU, PLS }\end{array}$ \\
\hline & $2 .{ }^{a}$ & Darb Naym & 8 & & $\begin{array}{l}\text { PND, PST, Wafd, } \\
\text { RNPU, PLS }\end{array}$ \\
\hline & $3 .^{2}$ & Abu Hammad & 10 & & $\begin{array}{l}\text { PND, PST, Wafd, } \\
\text { RNPU, PLS }\end{array}$ \\
\hline \multirow[t]{2}{*}{ Qalyubiyya } & 1. Norte & Benha & 10 & * & $\begin{array}{l}\text { PND, PST, Wafd, } \\
\text { RNPU, PLS }\end{array}$ \\
\hline & 2." Sur & Chubra al-Jayma & 10 & & $\begin{array}{l}\text { PND, PST, Wafd, } \\
\text { RNPU }\end{array}$ \\
\hline Kafr al-Chayj & 1 & Kafr al-Chayj & 14 & $*$ & $\begin{array}{l}\text { PND, PST, Wafd, } \\
\text { RNPU, PLS }\end{array}$ \\
\hline \multirow[t]{3}{*}{ Garbiyya } & $1 . .^{\mathrm{a}}$ & Awwal Tanta & 8 & * & $\begin{array}{l}\text { PND, PST, Wafd, } \\
\text { RNPU, PLS }\end{array}$ \\
\hline & 2. & Tanta & 10 & & $\begin{array}{l}\text { PND, PST, Wafd, } \\
\text { RNPU, PLS }\end{array}$ \\
\hline & $3 .^{a}$ & Awwal M. Al-Kubra & 8 & & $\begin{array}{l}\text { PND, PST, Wafd, } \\
\text { RNPU }\end{array}$ \\
\hline \multirow[t]{2}{*}{ Manufiyya } & 1. & Chabin al-Kum & 10 & * & $\begin{array}{l}\text { PND, PST, Wafd, } \\
\text { RNPU }\end{array}$ \\
\hline & $2 .{ }^{a}$ & Al-Bayur & 12 & & $\begin{array}{l}\text { PND, PST, Wafd, } \\
\text { RNPU }\end{array}$ \\
\hline
\end{tabular}

* Circunscripciones con escaño reservado para la mujer. 
Las candidaturas de los partidos (Continuación)

\begin{tabular}{|c|c|c|c|c|c|}
\hline Provincias & $\begin{array}{l}\text { Circunscrip- } \\
\text { ciones }\end{array}$ & Sedes & $\begin{array}{l}\text { Esca- } \\
\bar{n} o s\end{array}$ & $\begin{array}{l}\text { Muje- } \\
\text { res }\end{array}$ & Partidos \\
\hline \multirow[t]{3}{*}{ Buhayra } & 1." & Damanhur & 12 & * & $\begin{array}{l}\text { PND, PST, Wafd, } \\
\text { RNPU }\end{array}$ \\
\hline & $2 .^{a}$ & Kafr al-Dawar & 8 & & $\begin{array}{l}\text { PND, PST, Wafd, } \\
\text { RNPU }\end{array}$ \\
\hline & $3 .^{2}$ & Itay al-Barud & 8 & & $\begin{array}{l}\text { PND, Wafd, } \\
\text { RNPU }\end{array}$ \\
\hline Wadi al-Yadid & 1 & Wadi al-Yadid & 4 & $*$ & $\begin{array}{l}\text { PND, PST, RNPU, } \\
\text { PLS }\end{array}$ \\
\hline Marsa Matruh & 1 & Marsa Matruh & 4 & * & PND, PST, RNPU \\
\hline Sinaí Sur & 1 & Sinaí Sur & 4 & * & PND \\
\hline Sinaí Norte & 1 & Sinaí Norte & 4 & * & $\begin{array}{l}\text { PND, PST, Wafd, } \\
\text { RNPU }\end{array}$ \\
\hline
\end{tabular}

* Circunscripciones con escaño reservado para la mujer.

\section{LOS RESULTADOS ELECTORALES Y SU INTERPRETACION}

\section{La participación y el voto nulo}

La participación en las elecciones de mayo no alcanzó el 50 por 100: acudieron a las urnas el 43,14 por 100 de los electores registrados (12.339.417), con lo cual sólo ejercieron su derecho de voto en los comicios $5.323 .086^{35}$. Hay que hacer notar, sin embargo, el nuevo estilo que significa el reconocimiento y publicación por parte del Gobierno de estos datos, tan lejanos a los habituales porcentajes de participación de las elecciones de Nasser y Sadat, dando así credibilidad al nuevo proceso electoral.

Esta baja participación da idea del desinterés político e incluso de cierta desconfianza en la eficacia y sanidad del proceso, de los que no son ajenos ni la carencia desde hace más de treinta años de una tradición democrática y multipartidista que invitase a la participación del ciudadano a elegir a sus representantes políticos ni los altos índices de analfabetismo, que en el caso de las mujeres alcanza el 70 por 100 y en el de los hombres el 56 por 100, para los cuales la existencia de diferentes programas electorales no tiene ningún sentido.

${ }^{35}$ Los resultados electorales globales y por circunscripción fueron publicados en los periódicos Al-Abram y Al-Aibar del 30 mayo 1984 . La prensa de los partidos de la oposición no publicó los datos completos. 
Las cifras de participación en las diferentes provincias varían en algunos casos significativamente. En el centro urbano que engloba la provincia de Giza, el índice de participación fue muy bajo: 24,78 por $100^{36}$. El hecho de que no se hayan publicado los datos correspondientes a la provincia de El Cairo, de enorme importancia, quizá podría hacer suponer una cierta intención de enmascaramiento de la alta abstención en la misma, cuando vemos que también Alejandría, el tercer gran núcleo poblacional egipcio, ofrece una escasa participación: 27,93 por 100 .

Estos bajos porcentajes en los grandes centros urbanos, en los que la politización debe ser mayor, apuntarían hacia el desencanto y la desconfianza sobre la autenticidad de los avances democráticos en las elecciones.

Por el contrario, se observa una mayor participación en las dos provincias del Sinaí, Norte $(59,84$ por 100$)$ y Sur $(50,45$ por 100$)$, donde quizá no esté exenta de relación su reciente devolución a Egipto por parte de los israelíes, según los acuerdos de Camp David.

Los datos publicados de algunas provincias de la región del Delta, de carácter esencialmente rural, pero no por ello carente de algunos núcleos de población importantes, muestran una participación superior a la media: Buhayra, 47,49 por 100; Kafr al-Cheyj, 51,23 por 100; Qalyubía, 57,28 por 100. En Daqhaliyya, 36,12 por 100, estuvo por debajo de la media.

El porcentaje de mayor participación es el de Al-Fayum, 77,77 por 100, superando ampliamente al resto de las provincias, y en la que no hay que olvidar la ardiente campaña que allí realizó el ministro de Agricultura, candidato en este oasis básicamente agrícola, con futuras promesas de potenciación para esta zona.

En el lado opuesto, la provincia que registró la mayor abstención, dentro de los datos publicados, fue Suez, donde sólo se alcanzó un 19,80 por 100 de participación.

En lo que se refiere al voto nulo, se registraron 176.521 votos, el 3,3 por 100 de los emitidos. Los porcentajes de nulos en las diversas provincias oscilaron, menos en Giza, entre un 3,40 por 100 en Assiut y un 0,97 por 100 en el Sinaí Sur. En general, estas cifras no son significativas, a excepción del caso de Giza, cuyo porcentaje alcanzó el 6,57 por 100 , y, aunque vuelve a estar ausente el dato de El Cairo, este aumento de votos nulos, que duplica al más alto índice del resto de las provincias, podría indicar un significado político de votos conscientes que expresarían la desconfianza en el sistema electoral, fenómeno conocido en comicios de algún país árabe como Marruecos.

${ }^{36}$ Los datos son aproximativos, ya que corresponden sólo a dos circunscripciones de las tres que tenía la provincia de Giza. 


\section{Resultados por partidos}

Los datos más representativos en los resultados de las elecciones de mayo fueron la obtención por parte del PND de la mayoría absoluta, consiguiendo 391 escaños de los 448 que componen la Cámara, y el acceso a dicha Cámara de uno sólo de los otros cuatro partidos que se presentaban: el Wafd, único que traspasó la frontera del 8 por 100, consiguiendo los 57 escaños restantes.

De los 5.146 .565 votos válidos, el PND obtuvo el 72,98 por 100 ; el Wafd alcanzó el 10,11 por 100 ; el $P S T$, el 7,07 por 100 ; el RNPU, el 4,16 por 100 , y el $P L S$ no obtuvo más que el 0,64 por 100 .

El gran perdedor fue el $P L S$, cuya derrota no sorprendió a nadie, ya que presentaba muy pocos candidatos; pero la escasa diferencia que le faltó al PST para haber podido entrar en la Asamblea del Pueblo le habría permitido, en pura proporcionalidad, estar representado por 31 diputados. Para el RNPU hubiese significado 18 escaños, e incluso tres para el PLS.

En todos los distritos de la República ganó el PND, menos en Samamud, lugar de nacimiento del antiguo líder wafdista Mustafa al-Nahhas, donde fue éste el partido ganador.

Aparte del caso del Sinaí Sur, donde se presentaba solo y sacó el 100 por 100, el PND consiguió su porcentaje más alto de votos en Al-Fayum, con el 94,66 por 100 de los votos de esa provincia, cuya explicación estaría en las razones anteriormente mencionadas. El porcentaje más bajo fue en Port Said, lugar en el que alcanzó solamente el 46,66 por 100 y único sitio donde casi se igualó con el $W$ afd $(44,40$ por 100$)$, y donde quizá no estuviese carente de relación el malestar de esta población ante la intención del Gobierno de crear y potenciar otro puerto en la ciudad de Damieta.

En las provincias del Delta y en las desérticas obtuvo sus más altos porcentajes en general (Damieta, 87,96 por 100; Minufiya, 86,90 por 100; Qalyubiya, 84,29 por 100 ; Ismailiyya, 81,51 por 100 ; Charqiya, 79,61 por 100 ; Wadi al-Yadid, 83,10 por 100; Marsa Matruh, 80,47 por 100; Mar Rojo, 75,49 por 100; Sinaí Sur, 100 por 100 , y Sinaí Norte, 76,74 por 100).

Sin embargo, en El Cairo, Giza y Alejandría sus índices fueron más bajos que en las demás provincias, salvo escasas excepciones como Daqahliya, Suez y Assiut. En El Cairo obtuvo el 61,66 por 100 del total de los votos; en Giza, el 63,83 por 100, y en Alejandría, el 67,25 por 100 .

El Wafd, por el contrario, se verá más implantado en las zonas urbanas, como El Cairo, 25,96 por 100; Suez, 25,18 por 100; Garbiya, 24,66 por 100; Alejandría, 23,74 por 100; Giza, 22,80 por 100 , y Assiut, 22,50 por 100, provincia esta última en la que no hay que olvidar su población copta y su importancia como foco de integrismo musulmán. Su mayor porcentaje lo obtuvo, como se ha dicho, en Port Said, 44,4 por 100.

El PST consiguió su más alto porcentaje en el Mar Rojo, con un 24,50 por 100; Marsa Matruh, 17,17 por 100, y en Assiut, con el 10,96 por 100. 
El RNPU fue en Assuan donde logró llegar al 10,96 por 100, seguido de Daqahliya, con el 9,62 por 100 . En El Cairo obtuvo el 4,96 por 100 , y en Giza, el 7,82 por 100, para después disminuir considerablemente en el resto de las provincias.

El PLS llegó al 1,39 por 100 en Port Said, siendo su porcentaje más bajo en Damieta, con el 0,15 por 100.

Según indicaba la Ley Electoral, los 31 escaños de la mujer fueron para el partido vencedor, es decir, para el $P N D$. Trece eran rostros nuevos en la Cámara, 16 pertenecían a la categoría profesional y 15 a la obrera, no habiendo ninguna campesina.

Entre los miembros del Gobierno que fueron elegidos en las listas del $P N D$ se encontraban el primer ministro y 15 ministros.

\section{Resultados generales}

Electores inscritos

Votantes

Votos nulos

Votos válidos
12.339 .417

$5.323 .086 \quad(43,14 \%)$

$176.521 \quad(3,31 \%)$

5.146 .565

\begin{tabular}{|c|c|c|c|c|c|}
\hline Partidos & Votos & $\%$ votos & Escaños & \% escaños & $\begin{array}{l}\text { Votos por } \\
\text { diputado }\end{array}$ \\
\hline $\begin{array}{llllll}P N D & \ldots & \ldots & \ldots & \ldots & \ldots\end{array}$ & 3.756 .359 & 72,98 & 391 & 87,27 & 9.607 \\
\hline 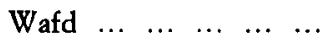 & 778.131 & 10,11 & 57 & 12,72 & 13.651 \\
\hline $\begin{array}{lllllll}\text { PST } & \ldots & \ldots & \ldots & \ldots & \ldots & \ldots\end{array}$ & 364.040 & 7,07 & - & - & - \\
\hline $\begin{array}{llllll}\text { RNPU } & \ldots & \ldots & \ldots & \ldots & \ldots\end{array}$ & 214.587 & 4,16 & - & - & - \\
\hline $\begin{array}{lllllll}\underline{\operatorname{PLS}} & \ldots & \ldots & \ldots & \ldots & \ldots & \ldots\end{array}$ & 33.448 & 0,64 & - & - & - \\
\hline $\begin{array}{lllllll}\bar{X} & \ldots & \ldots & \ldots & \ldots & \ldots & \ldots\end{array}$ & - & - & - & - & 11.487 \\
\hline
\end{tabular}

FUENTE: Al-Abram, 30 mayo 1984. 
Resultados por provincias

\begin{tabular}{|c|c|c|c|c|c|c|c|c|c|c|c|}
\hline Provincias & $\begin{array}{l}\text { \% parti- } \\
\text { cipación }\end{array}$ & $\begin{array}{l}\% \\
\text { nulo }\end{array}$ & $\begin{array}{c}\% \\
P N D\end{array}$ & $\begin{array}{c}\% \\
\text { Wafd }\end{array}$ & $\begin{array}{c}\% \\
P S T\end{array}$ & $\begin{array}{c}\% \\
\text { RNPU }\end{array}$ & $\begin{array}{l}\% \\
P L S\end{array}$ & $\begin{array}{l}\text { Número } \\
\text { escaños } \\
\text { PND }\end{array}$ & $\begin{array}{c}\% \\
\text { escaños } \\
\text { PND }\end{array}$ & $\begin{array}{l}\text { Número } \\
\text { escaños } \\
\text { Wafd }\end{array}$ & $\begin{array}{c}\% \\
\text { escaños } \\
\text { Wafd }\end{array}$ \\
\hline $\begin{array}{lllllll}\text { El Cairo } & \ldots & \ldots & \ldots & \ldots\end{array}$ & - & - & 61,66 & 25,96 & 7,04 & 4,96 & 0,19 & 41 & 76 & 13 & 24 \\
\hline $\begin{array}{llllll}\text { Giza } & \ldots & \ldots & \ldots & \ldots & \ldots\end{array}$ & 24,78 * & $6,57 *$ & 63,83 & 22,80 & 7,82 & 4,98 & - & 20 & 77 & 6 & 23 \\
\hline $\begin{array}{lllll}\text { Alejandría } & \ldots & \ldots & \ldots & \ldots\end{array}$ & 27,93 & 3,30 & 67,25 & 23,74 & 2,45 & 5,78 & 0,75 & 21 & 80,8 & 5 & 19,2 \\
\hline $\begin{array}{lllll}\text { Buhayra } & \ldots & \ldots & \ldots & \ldots\end{array}$ & $47,49 *$ & - & 71,44 & 18,77 & 5,60 & 3,88 & - & 24 & 85,7 & 4 & 14,3 \\
\hline Kafr al-Chayj $\ldots . . .$. & $51,23 *$ & $2,95 *$ & 76,19 & 13,02 & 5,10 & 1,96 & 1,17 & 12 & 85,7 & 2 & 14,3 \\
\hline 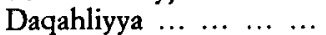 & 36,12 * & - & 66,79 & 11,38 & 11,50 & 9,62 & 0,69 & 29 & 90,63 & 3 & 9,37 \\
\hline 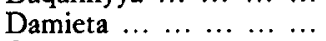 & - & - & 87,96 & 8,64 & 13,88 & 2,31 & 1,15 & 8 & 100 & - & - \\
\hline $\begin{array}{ccccc}\text { Charqiyya } & \ldots & \ldots & \ldots & \ldots\end{array}$ & - & - & 79,61 & 11,58 & 3,78 & 4,07 & 0,53 & 27 & 90 & 3 & 10 \\
\hline $\begin{array}{llllll}\text { Garbiyya } & \ldots & \ldots & \ldots & \ldots\end{array}$ & - & - & 70,10 & 24,63 & 2,34 & 2,76 & - & 22 & 84,6 & 4 & 15,4 \\
\hline $\begin{array}{lllll}\text { Manufiyya } & \ldots & \ldots & \ldots & \ldots \\
\end{array}$ & - & - & 86,90 & 7,96 & 3,84 & 1,28 & - & 22 & 100 & - & - \\
\hline $\begin{array}{ccccc}\text { Qalyubiyya } & \ldots & \ldots & \ldots & \ldots\end{array}$ & 57,28 & 2,32 & 84,29 & 5,59 & 6,75 & 3,27 & - & 20 & 100 & - & - \\
\hline Wadi al-Yadid $\ldots \ldots \ldots$ & - & 2,03 & 83,10 & - & 16,08 & 0,45 & - & 4 & 100 & - & - \\
\hline Port Said $\ldots \ldots \ldots$ & - & 3,96 & 46,66 & 44,40 & 2,81 & 4,71 & 1,39 & 4 & 66,6 & 2 & 33,3 \\
\hline $\begin{array}{lllll}\text { Ismailiyya } & \ldots & \ldots & \ldots & \ldots\end{array}$ & 39,57 & 3,83 & 81,51 & 8,84 & 9,64 & - & - & 6 & 100 & - & - \\
\hline $\begin{array}{lllllll}\text { Suez } & \ldots & \ldots & \ldots & \ldots & \ldots & \ldots\end{array}$ & 19,80 & 1,99 & 64,84 & 25,18 & 2,15 & 6,73 & 1,08 & 3 & 75 & 1 & 25 \\
\hline Sinai Norte $\ldots \ldots \ldots \ldots$ & 59,84 & 3,16 & 76,74 & 14,34 & 6,83 & 2,73 & - & 4 & 100 & - & - \\
\hline $\begin{array}{llllll}\text { Sinaí Sur } & \ldots & \ldots & \ldots & \ldots\end{array}$ & 50,45 & 0,97 & 100 & - & - & - & - & 4 & 100 & - & - \\
\hline $\begin{array}{lllll}\operatorname{Mar} \operatorname{Rojo} & \ldots & \ldots & \ldots & \ldots\end{array}$ & $38,34 *$ & - & 75,49 & - & 24,50 & - & - & 4 & 100 & - & - \\
\hline $\begin{array}{lllll}\text { Al-Fayum } & \ldots & \ldots & \ldots & \ldots\end{array}$ & 77,77 & 1,27 & 94,66 & 2,29 & 1,12 & 1,74 & 0,20 & 14 & 100 & - & - \\
\hline $\begin{array}{lllll}\text { Beni Suef } & \ldots & \ldots & \ldots & \ldots\end{array}$ & - & - & 72,22 & 19,32 & 5,76 & 2,22 & 1,11 & 12 & 85,7 & 2 & 14,3 \\
\hline $\begin{array}{lllll}\text { Al-Minya } & \ldots & \ldots & \ldots & \ldots\end{array}$ & - & - & 81,77 & 10,76 & 5,31 & 1,88 & 0,25 & 22 & 91,7 & 2 & 8,3 \\
\hline $\begin{array}{llllll}\text { Assiut } & \ldots & \ldots & \ldots & \ldots & \ldots\end{array}$ & $36,84 *$ & 3,40 & 65,29 & 22,50 & 10,96 & 1,22 & - & 15 & 75 & 5 & 25 \\
\hline $\begin{array}{llllll}\text { Suhay } & \ldots & \ldots & \ldots & \ldots & \ldots\end{array}$ & - & - & $71,49 *$ & $11,33 *$ & $10,75 *$ & 1,78 * & $0,77 *$ & 21 & 87,5 & 3 & 12,5 \\
\hline $\begin{array}{llllll}\text { Qena } & \ldots & \ldots & \ldots & \ldots & \ldots\end{array}$ & - & - & 78,35 & 8,10 & 9,32 & 4,20 & - & 20 & 90,9 & 2 & 9,09 \\
\hline $\begin{array}{lllllll}\text { Aswan } & \ldots & \ldots & \ldots & \ldots & \ldots\end{array}$ & - & - & 74,33 & 8,05 & 6,17 & 10,92 & 0,51 & 8 & 100 & - & - \\
\hline Marsa Matruh ... ... ... & 32,62 & 2,81 & 80,47 & - & 17,17 & 2,35 & - & 4 & 100 & - & - \\
\hline
\end{tabular}

* Los datos son aproximativos.

FuENTES: Al-Abram y Al-Ajbar, 30 mayo 1984. 
Los miembros por designación de la Asamblea del Pueblo

La Constitución egipcia establece que diez miembros de la Asamblea del Pueblo son elegidos por el presidente de la República.

Desde las elecciones de 1964, Nasser inició la tradición de destinar la mayor parte de estos escaños a la minoría copta para asegurar su participación, costumbre que el presidente Sadat también mantuvo.

El presidente Mubarak, continuando con la misma iniciativa, ha designado para la mitad de los diez escaños a personalidades coptas.

El resto de estos escaños fueron atribuidos por el presidente a algunos miembros de la oposición entre los partidos del PST y el RNPU, que no habían podido superar el 8 por 100, pero sí habían obtenido un número de votos significativo.

Con respecto al RNPU, desde un comienzo su secretario general, Jaled Muhieddin, declaró que su partido rechazaría tal ofrecimiento, y así ocurrió cuando llegó el momento. Este partido publicó un editorial en su periódico, "Por qué hemos rechazado el nombramiento en la Asamblea del Pueblo» ${ }^{37}$, en el que explicaba que perdería su credibilidad ante el pueblo si aceptaba ser elegido por el partido gubernamental, cuya política económica (infitab), sus leyes discriminatorias (Ley de Excepción y de Secretos de Estado) y su política exterior (Camp David) se oponen radicalmente a su ideología.

Sin embargo, el doctor Milad Hanna, perteneciente a este partido y copto, quiso aceptar el escaño en la Asamblea, pero tuvo que hacerlo a nivel individual, ya que el partido se negó a reconocerlo como representante suyo.

El caso del PST fue más polémico, pues su presidente, Ibrahim Chukri, también declaró en un principio que su partido no aceptaría los nombramientos que se pudieran ofrecer a sus miembros. Tras una serie de enfrentamientos internos, el partido acabó aceptando la denominación de tres diputados en la Asamblea del Pueblo.

\section{A MANERA DE CONCLUSION}

Como se apuntaba al comienzo de este trabajo, el análisis de las elecciones legislativas de mayo de 1984 en Egipto nos podía permitir la comprobación de hasta qué punto estas elecciones han supuesto un paso hacia una transición democrática.

Para ello, la primera verificación a tener en cuenta es el grado de competitividad de las mismas.

$\mathrm{Si}$, según indica Dieter Nohlen ${ }^{38}$, «elección» se ha de entender como se-

37 Al-Abali, 6 junio 1984, p. 8 .

${ }^{38}$ Dieter No H LEN, Sistemas electorales del mundo, Madrid, 1981, p. 22. 
lección y libertad de elección, los últimos comicios llevados a cabo en Egipto significan un considerable avance con respecto a los períodos anteriores. En el caso de las elecciones nasseristas, el elector sólo podía optar entre unos candidatos ya seleccionados por el Comité Ejecutivo del partido único. Se trataba, en definitiva, de un sistema no competitivo. Sadat, a pesar de su inicial aperturismo, siguió reduciendo en la realidad el juego político a las fuerzas dentro del mismo régimen. En las elecciones de 1984, bajo la presidencia de Mubarak, participa un partido prerrevolucionario como el Wafd $\mathrm{y}$, de su mano, una importante fuerza ideológica y social como los Hermanos Musulmanes, asociaciones ambas prohibidas por Nasser y que habían quedado excluidas totalmente del régimen que nació del 26 de julio de 1952. En esta ocasión se han incorporado otras fuerzas políticas de una oposición real que han permitido al elector una selección diversificada entre ideologías diferentes expresadas en sus programas.

El nuevo sistema electoral trajo consigo otro aspecto positivo. Frente al anterior sistema de mayoría absoluta, se amplían las posibilidades para los partidos de oposición de acceder a la Cámara. Si bien una de las condiciones que más deslucieron esta apertura democrática fue la traba del 8 por 100 que imponía la Ley Electoral, y que motivó que tres de los cinco partidos en competencia quedaran fuera de la Asamblea en las elecciones directas -contribuyendo a reducir el sistema a un nivel semicompetitivo-, es necesario decir que la oposición pudo realizar una presión efectiva y, a través de sus órganos de prensa, criticar y valorar sin ningún tipo de censura la gestión del Gobierno penedista.

Es necesario reseñar que este 8 por 100 respondía al deseo por parte del PND de asegurarse una mayoría absoluta en la Cámara, con vistas a las elecciones presidenciales que se realizarán en 1988, evitando las posibles coaliciones a las que se vería obligado para conseguir la reelección del presidente, que necesita los dos tercios de la Asamblea.

Otro hecho a constatar es que el $W$ afd ha sido el segundo partido votado, lo que demuestra que ha sobrevivido a la ausencia de treinta años, permaneciendo en la memoria colectiva como depositario de una cierta lucha patriótica y de un liberalismo que se acabó con el golpe de los «Oficiales Libres».

Es difícil a la luz de los datos hechos públicos por el Ministerio del Interior, por la falta de sondeos preelectorales y la ausencia de una tradición de elecciones libres que permita establecer comparaciones, llegar a establecer una aproximación a las radiografías del electorado de los principales partidos egipcios. Por el simple estudio de los programas electorales pueden verse diferencias notables en algunos casos entre las presumibles fuerzas sociales que pudieran apoyar a ciertos partidos: burguesía burocrática al $P N D$, pequeña burguesía tradicional urbana y restos de una burguesía agraria al Watd, así como sectores obreros al RNPU. Todo ello podría ser una deducción de los programas económicos concurrentes, pero no pasa de ser una mera hipótesis. 
Otro aspecto de los programas permite pensar que el electorado de estos mismos partidos podría ser interclasista. El mero estudio de los datos sólo permite constatar el incremento del voto $W$ afd con el mayor grado de urbanización de las circunscripciones electorales, lo que le identificaría con un electorado de mayor nivel de politización y cultura, ya que, paralelamente, se observa la disminución del voto $P N D$ en estas mismas circunscripciones, voto que se supone más ligado a la influencia de la Administración. Se ha señalado en el trabajo, en relación con esto mismo, el aumento de la abstención como correlativo del fenómeno de la urbanización, de lo que podría deducirse que la credibilidad del sistema político de Mubarak se mantiene en unos niveles de continuismo en sus líneas básicas que no cuenta con el apoyo de los sectores conscientes de la población.

En lo que respecta a los importantes resultados obtenidos por el Wafd, cabría ver quizá la expresión de la esperanza de cambio de algunas clases sociales egipcias descontentas de la trayectoria económica y política de las últimas décadas, sin que su alianza con los Hermanos Musulmanes permita delimitar con claridad el componente «liberal» del voto del componente islámico.

Sólo nuevos procesos electorales permitirán ver si esta alianza táctica sobrevivirá a la legislatura, influyendo claramente en el carácter del partido, o si, por el contrario, deslindará los dos componentes señalados, viéndose la influencia de cada uno de ellos. 